\title{
PROGRESSIVE COLLAPSE ANALYSIS OF TRANSMISSION TOWER-LINE SYSTEM UNDER EARTHQUAKE
}

\author{
W.M. Wang ${ }^{1, *}$, H.N. $\mathrm{Li}^{2}$ and L. $\operatorname{Tian}^{3}$ \\ ${ }^{1}$ Faculty of Infrastructure Engineering, Dalian University of Technology, Dalian, PR China \\ ${ }^{2}$ Professor, Faculty of Infrastructure Engineering, Dalian University of Technology, Dalian, PR China \\ ${ }^{3}$ School of Civil and Hydraulic Engineering, Shandong University, Jinan, PR China \\ *(Corresponding author: E-mail: wangwenming87110@163.com)
}

Received: 11 July 2012; Revised: 30 October 2012; Accepted: 5 December 2012

\begin{abstract}
High-voltage electric transmission tower may collapse under the strong earthquake and studies on the collapse mechanism, routine and capacity of transmission tower-line system are important for the structural design of tower. In this paper, a progressive collapse analytical procedure for the system is proposed based on the finite element method (FEM). During this procedure, the mass of the elements is still retained rather than removal after elements lose the load-bearing capacity. The proposed procedure is coded using the user subroutine VUMAT and then implemented in the advanced finite element program ABAQUS. A three-dimensional finite element model for the system of three towers and four-span lines is created. By using the coded subroutine, the collapse analysis of the tower-line system under the strong earthquake is performed. Collapse processes along longitudinal and lateral direction are studied, respectively. Furthermore, the influences of ultimate strain and strain rate effect of materials on the collapse mode and capacity are studied. The results indicate that the collapse analysis of the tower-line system by using the proposed procedure can provide collapse mode and vulnerable points for use in seismic performance and retrofit evaluation of structure. It is found from the numerical modeling that the influences of ground motion and ultimate strain on the collapse modes are apparent. The collapse-resistant capacity of system increases remarkably with the increase of ultimate strain and influences of strain rate on collapse routine and capacity are tiny in analytical results.
\end{abstract}

Keywords: Tower-line system, collapse analysis, collapse routine, collapse-resistant capacity, vulnerable points, ultimate strain, strain rate

\section{INTRODUCTION}

Overhead high-voltage electric transmission lines play an important role in the operation of a reliable electrical power system, whose damage can cause great economic loss and bring inconvenience to human life ( $\mathrm{Li}$ and Bai [1]; Xie and $\mathrm{Li} \mathrm{[2]).} \mathrm{A} \mathrm{substantial} \mathrm{number} \mathrm{of} \mathrm{transmission}$ lines were damaged by catastrophic earthquakes around the world. The transmission tower tilt or collapse, conductor breakage, foundation subsidence and insulator destruction were the major types of failure. It is necessary to study not only the seismic response of transmission lines in the elastic and plastic phase, but also their collapse process. Progressive collapse analysis is a well-understood physical occurrence in which loss of local load-bearing capacity propagates through a system, precipitating complete collapse or a major portion of it. Vulnerable points, collapse mode and capacity of structure can be evaluated by it, which can be used for the design of new towers or for evaluating existing towers.

Over past years, many scholars have studied the nonlinear responses of single transmission tower or tower-line system ( $\mathrm{Li}$ et al. [3]; Albermani et al. [4]; Rao et al. [5]). Li et al. investigated the ultimate status of several transmission tower-line systems under earthquake using the simplified model in which lines were treated as concentrated mass (Li et al. [3]). That means the coupling effects between towers and lines cannot be considered. Alberman et al. presented a non-linear methodology considering both material and geometric non-linearity, and applied it to a new transmission tower (Albermani et al. [4]). The proposed methodology was proved to be accurate enough to predict structural failure by calibrating with the results from the full-scale tower test. Rao 
et al. presented different types of premature failures of transmission towers observed during full-scale testing and pointed out their mechanisms (Rao et al. [5]). However, there is no study related to the progressive collapse analysis of transmission tower-line system under earthquake.

Current civil engineering practice prefers to use the FEM for structural analysis. During the collapse process under earthquake, some elements lose load-bearing capacity, which is a problem for the FEM. Commonly, the method removing these elements is used, which is called the birth-death element method. With the method, some elements are removed during the simulation process, which is not agree with realistic situation. The method retaining the mass of these elements rather than removal is proposed.

The main objective of this investigation is to study the collapse process of a transmission tower-line system using the approach proposed in the paper. First, numerical methods for the progressive collapse used before and proposed are introduced. The proposed procedure is then used for a transmission tower-line system. Collapse processes along longitudinal and lateral direction under different earthquake excitations are studied and influences of ultimate strain and strain rate effect on the collapse mode and capacity are analyzed.

\section{BRIEF INTRODUCTION OF COLLAPSE SIMULATION METHODS}

Numerical simulation of progressive collapse is a challenging task, which includes the material and geometrical non-linearity, contact and collision between elements, losing load-bearing capacity of elements and so on. Nowadays, there are mainly four numerical analytical methods used for the collapse analysis: the discrete element method (DEM), combined finite-discrete element method, applied element method (AEM) and FEM.

The DEM was initially developed for the study of jointed rock systems in 1971 (Cundall and Strack [6]), in which individual material element was considered to be separate and was connected only along its boundaries by frictional contact. With an introduction of joint-spring that represented the continuity of material, Meguro and Hakuno (Meguro and Hakuno [7]) developed an extended DEM (EDEM), which might be used for complex or heterogeneous materials such as concrete. Due to its capacity to explicitly represent the motion of multiple and intersecting discontinuities, the method is particularly suitable for analysis of the structure consisting of granular materials. However, it has not been used for the collapse analysis of large and complex structures due to its low efficiency and modeling complexity.

The combined finite-discrete element method is a recently developed numerical method aimed at modeling fracturing and failing elements, which combines aspects of both finite elements and discrete elements (Munjiza et al. [8]). In the method, solid domains are discretized into finite elements in the usual way dictated by the FEM, and contact between interacting domains is defined in a similar way to the DEM. The method can concentrate the advantages of FEM and DEM and has been applied to a wide range of engineering problems. However, each particular application requires the development of specific algorithmic procedures (Munjiza et al. [9]).

The AEM, which can predict the behaviors of structure from zero loading to collapse in a reasonable CPU time, is an innovative method adopting the concept of discrete cracking (Meguro and Tagel-Din [10]; Meguro and Tagel-Din [11]). With the AEM, a structure is modeled as an assembly of relatively small rigid elements that are connected by pairs of normal and shear springs loacted at contact points. With the AEM, crack initiation and propagation in the material can be predicted, the rigid body motion and the collision process can also be modeled. 
The FEM, based on continuum mechanics, is the most widely used method in structure engineering. For the linear elastic problems, the method has been proved to be advantageous. Furthermore, the method is very effective for solving nonlinear problems by using reasonable constitutive relationship. The method can be used in the solution of large scale and complex industrial problems, while other methods are extremely difficult to be used.

\section{PROPOSED METHOD}

Nowadays, the FEM is the only numerical method that has been used for transmission tower, which is used here also. The method can be divided into the explicit finite element method (EFEM) and implicit finite element method (IFEM) according to whether a new value is related to other new values in each increment step. The IFEM is unconditional stable, but the computational cost in the tangent stiffness matrix increases dramatically as the material non-linearity increases. The EFEM is conditional stable, and can overcome the disadvantage of the IFEM mentioned above. The CPU cost is approximately proportional to the size of the model (Sun et al. [12]). Therefore, the EFEM is more suited for the collapse analysis of complex and large projects.

For the transmission tower-line system, the non-linear dynamic analysis should be used because of its importance and complexity. The motion equation of structure under the seismic excitation is as follows:

$M(t) \ddot{x}(t)+C(t) \dot{x}(t)+K(t) x(t)=-M(t) \ddot{x}_{g}(t)$

where $\ddot{x}(t), \dot{x}(t)$ and $x(t)$ are the relative acceleration, velocity and displacement vectors; $\ddot{x}_{g}(t)$ is the acceleration vector of ground motion; $M(t), K(t)$ and $C(t)$ are the mass, stiffness and damping matrices, respectively. Generally, $M(t)$ is an invariant, while $K(t)$ and $C(t)$ change during the earthquake.

During the collapse process under earthquake, some elements lose load-bearing capacity one after another. Commonly, the birth-death element method is used (Lu et al. [13]; Kwasniewski [14]; Marjanishvili and Aganew [15]), in which these elements no longer contribute to $M(t)$ and $K(t)$. However, it has been already noticed that these elements still attached to the structure especially for the transmission tower. In other words, these elements still contribute to $M(t)$. The analytical approach of removing these elements is unsuiable, especially if the mass of these elements is unneglectable compared to the mass of the whole structure. The method considering the mass of these elements is more reasonable, which is the proposed method.

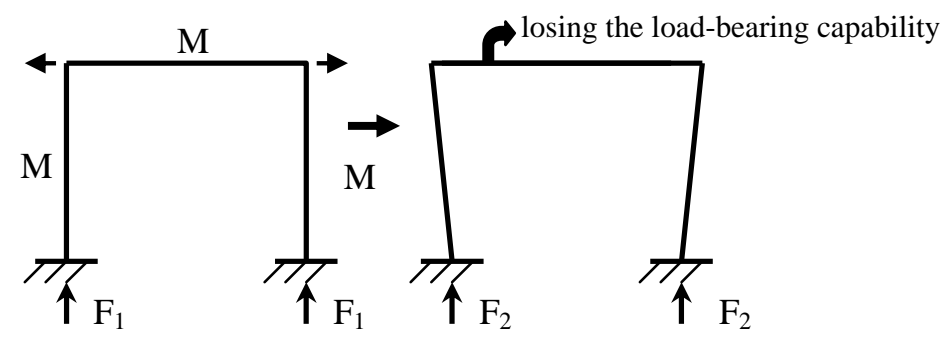

Figure 1. Description of the Model and the Loading Mode 
The rationality of the proposed method is illustrated with a case study. The description of the model and the loading mode are shown in Figure 1. The used model contains three components, with the same section and the same mass $\mathrm{M}$. The reaction force $\mathrm{F}_{1}$ is equal to $1.5 \mathrm{Mg}$ before loading. With the proposed method, the reaction force $F_{2}$ is equal to $1.5 \mathrm{Mg}$ after loading also. If the birth-death element method is used, the reaction force $F_{2}$ is equal to $1.0 \mathrm{Mg}$ after loading. In most cases, the beam still attaches to the columns after losing load-bearing capacity. Therefor, the proposed method is more rational than the birth-death element method.

\section{PROGRAM DEVELOPMENT FOR PROGRESSIVE COLLAPSE SIMULATION}

Elastic-perfectly plastic material model is used, which is shown in Figure 2. The constitutive relationship is coded using the user subroutine VUMAT (ABAQUS Inc. [16]), which can be implemented in the advanced finite element program ABAQUS. According to the proposed method, once the strain exceeds ultimate strain, the stiffness of the element is zero while the mass is still retained.

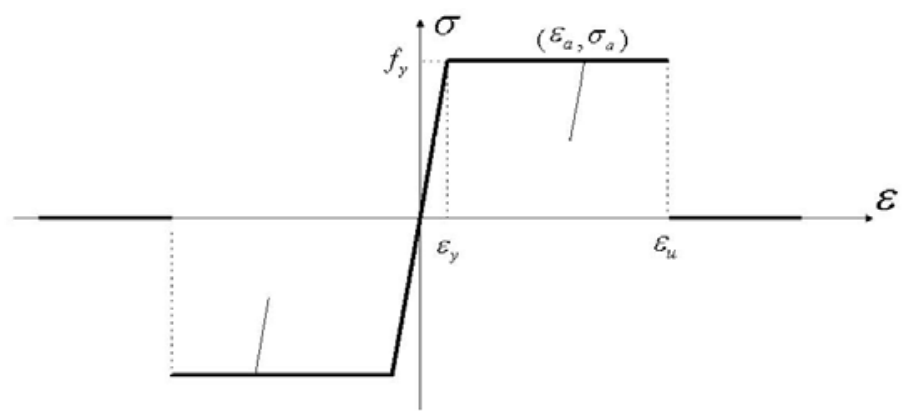

Figure 2. Stress-Strain Curve of Steel

For uniaxial loading, the stress-strain relationship of steel is as follows:

$\sigma=\left\{\begin{array}{cc}E_{s} \varepsilon & \varepsilon \leq \varepsilon_{y} \\ f_{y} & \varepsilon_{y} \leq \varepsilon \leq \varepsilon_{u} \\ 0 & \varepsilon>\varepsilon_{u}\end{array}\right.$

Where $\varepsilon$ and $\sigma$ are the strain and stress; $E_{s}$ is the elastic modulus; $\varepsilon_{y}$ and $f_{y}$ are the yield strain and yield stress; $\varepsilon_{u}$ is the ultimate strain.

For cyclic loading, the stress-strain relationship is as follows:

$\sigma=\sigma_{a}+E_{s}\left(\varepsilon-\varepsilon_{a}\right)$

Where $\sigma_{a}$ and $\varepsilon_{a}$ are the stress and strain of the starting point in the unloading curve.

\section{DESCRIPTION OF THE SELECTED STRUCTURE}

The selected tower for the collapse analysis is illustrated in Figure 3, which has a height of $60.5 \mathrm{~m}$ from the ground and a square base area of $10.16 \mathrm{~m} \times 10.16 \mathrm{~m}$ at ground level. The angle steel with equal section is used for all tower members. Main members of the tower are made of Q345, and secondary members Q235. The mechanical properties of Q345 and Q235 are shown in Table 1. 


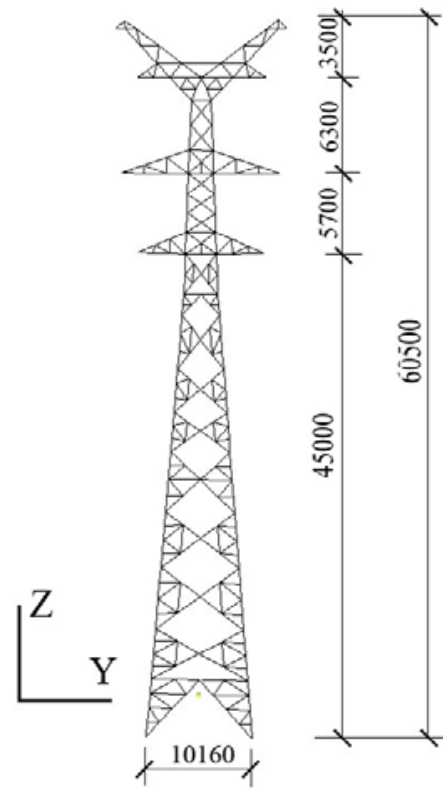

Figure 3. Transverse View of a Transmission Tower (mm)

Table 1. Mechanical Properties of Q345 and Q235

\begin{tabular}{ccccc}
\hline Material & $\begin{array}{c}\text { Yield stress } \\
(\mathrm{Pa})\end{array}$ & $\begin{array}{c}\text { Young's modulus } \\
(\mathrm{Pa})\end{array}$ & Poisson's ratio & $\begin{array}{c}\text { Density } \\
\left(\mathrm{Kg} / \mathrm{m}^{3}\right)\end{array}$ \\
\hline Q345 & $3.45 \mathrm{E}+08$ & $2.00 \mathrm{E}+11$ & 0.3 & 7800 \\
Q235 & $2.35 \mathrm{E}+08$ & $2.00 \mathrm{E}+11$ & 0.3 & 7800 \\
\hline
\end{tabular}

A transmission line system consists of many towers and lines, and the coupling effects of tower and line are prominent. However, it is unrealistic to use a model that includes all towers and lines. Here, the used model contains three towers and four-span lines, which was verified to be reasonable (Shen et al. [17]; Tian et al. [18]). The schematic view of the model is shown in Figure 4, in which the conductors and towers are connected with insulators and the materials for conductor and ground wire are steel-cored aluminium strand. The properties and performance indices of conductor, ground wire and insulator are depicted in Table 2.

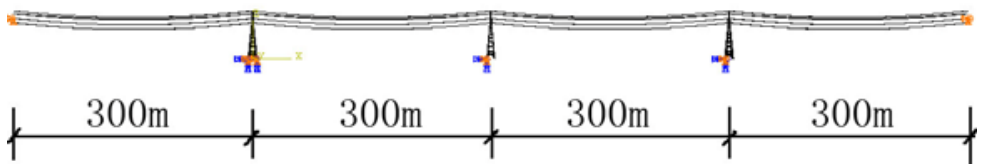

Figure 4. Three-Dimensional Finite Element Model of Tower-Line System

Table 2. Properties and Performance Indices of Conductor, Ground Wire and Insulator

\begin{tabular}{cccccc}
\hline Type & Area $\left(\mathrm{m}^{2}\right)$ & $\begin{array}{c}\text { Young's modulus } \\
(\mathrm{Pa})\end{array}$ & Poisson's ratio & $\begin{array}{c}\text { Density } \\
\left(\mathrm{Kg} / \mathrm{m}^{3}\right)\end{array}$ & $\begin{array}{c}\text { Yield force } \\
(\mathrm{N})\end{array}$ \\
\hline Conductor & $4.25 \mathrm{E}-04$ & $6.50 \mathrm{E}+10$ & 0.3 & 3172 & 98710 \\
Ground wire & $1.53 \mathrm{E}-04$ & $1.05 \mathrm{E}+11$ & 0.3 & 4631 & 74200 \\
Insulator & 0.02 & $7.65 \mathrm{E}+10$ & 0.2 & 7500 & 1000000 \\
\hline
\end{tabular}

The three dimensional beam elements type, B31, with three translational and three rotational degrees of freedom per node is employed to model the tower members, and the three dimensional truss elements type, T3D2, with three translational degrees of freedom per node is applied to model the lines and insulators in the ABAQUS software. Each tower contains 741 beam elements, each insulator contains one element, and the mesh selected for each conductor and ground wire consists of 100 truss elements. 


\section{PROGRESS COLLAPSE ANALYSIS OF TRANSMISSION TOWER-LINE SYSTEM}

\subsection{Earthquake Ground Motions Selected}

The method of dynamic time history analysis is used to assess the structural response. Here, three ground acceleration records are chosen for collapse analysis: (1) Kobe wave (1995); (2) Northbridge wave (1994); (3) El Centro wave (1940). To obtain the collapse process of the model, the peak ground accelerations are set equal to $20 \mathrm{~m} / \mathrm{s}^{2}, 40 \mathrm{~m} / \mathrm{s}^{2}$ and $25 \mathrm{~m} / \mathrm{s}^{2}$, respectively.

\subsection{Collapse Analysis Along Longitudinal Direction}

For nonlinear dynamic problems, the ABAQUS offers two integration methods including the implicit and explicit methods. The later is selected for analytical simulation based on the proposed approach. In this section, seismic records are input along longitudinal direction, and the ultimate strain of materials takes 0.02 . For transmission tower-line system, geometrical nonlinearity is prominent, which is considered in the analysis.

For the tower-line system, the middle tower is used for analyses of collapse process under Kobe, Northbridge and El Centro waves, and results are shown in Figure 5, Figure 6 and Figure 7, respectively. To show the collapse process more clearly, lines, insulators and the elements that lost the load-bearing capacity are removed from the figures.

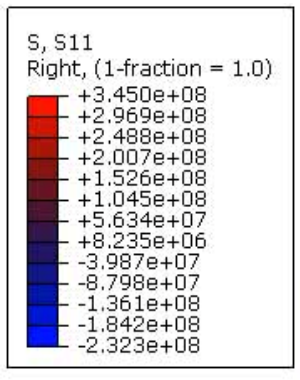

(a) $\mathrm{t}=6 \mathrm{~s}$

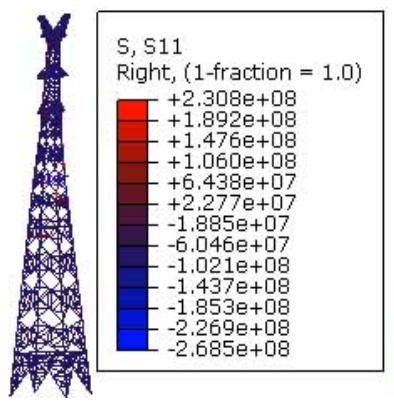

(b) $\mathrm{t}=7 \mathrm{~s}$

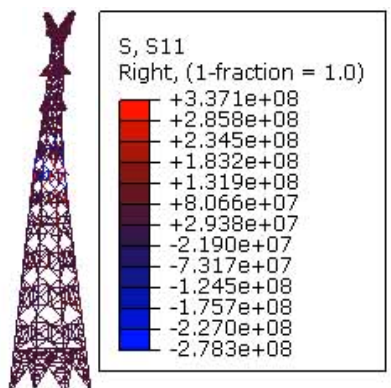

(c) $\mathrm{t}=9 \mathrm{~s}$

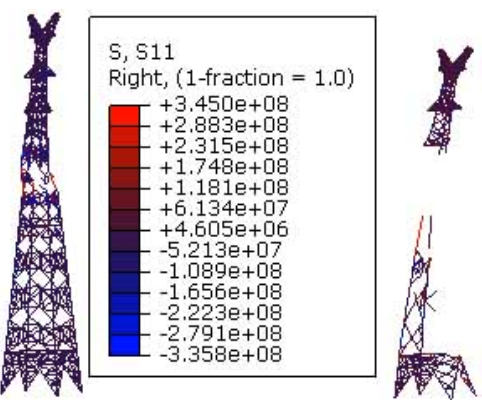

(d) $\mathrm{t}=10 \mathrm{~s}$

Figure 5. Collapse Process of the Middle Tower Along Longitudinal Direction Under Kobe Wave

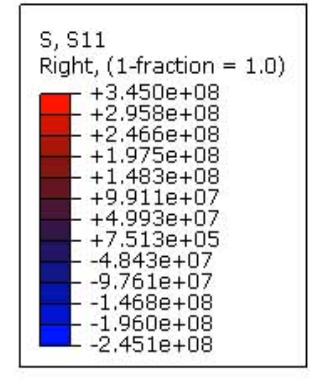

(a) $\mathrm{t}=4 \mathrm{~s}$

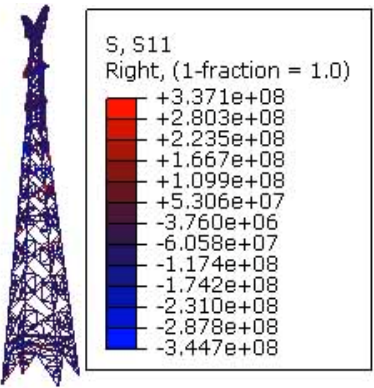

(b) $t=5 \mathrm{~s}$

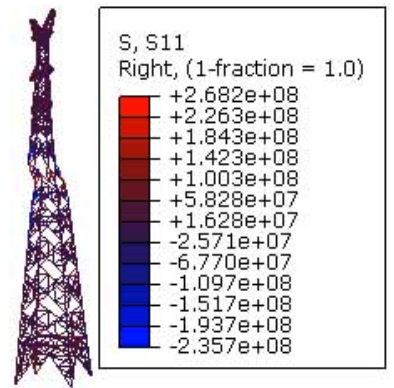

(c) $\mathrm{t}=5.2 \mathrm{~s}$

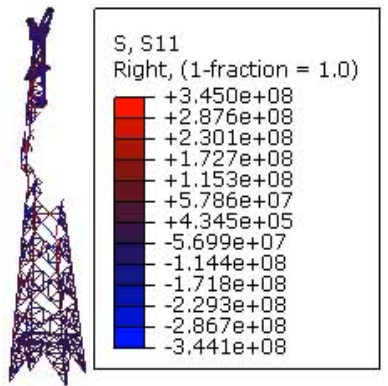

(d) $\mathrm{t}=5.5 \mathrm{~s}$

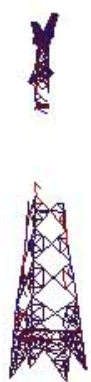

Figure 6. Collapse Process of the Middle Tower Along Longitudinal Direction Under Northbridge Wave 


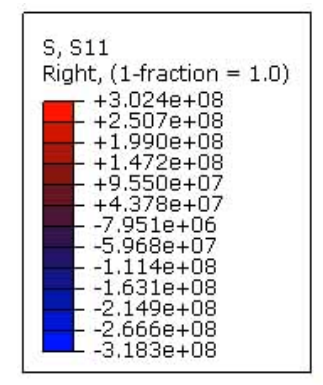

(a) $\mathrm{t}=9 \mathrm{~s}$

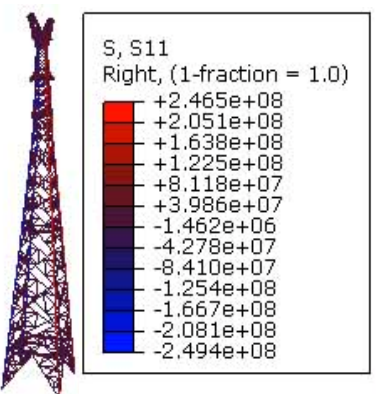

(b) $\mathrm{t}=9.5 \mathrm{~s}$

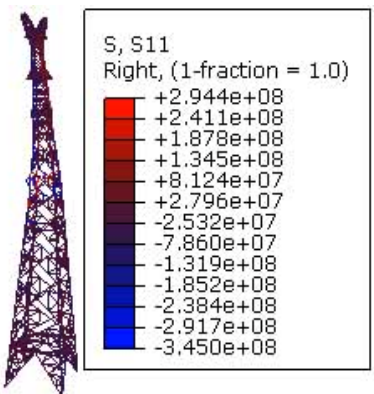

(c) $\mathrm{t}=9.8 \mathrm{~s}$

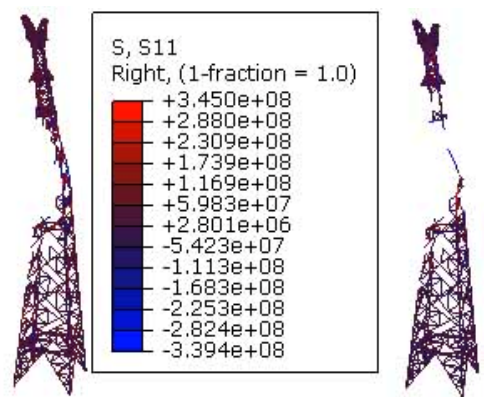

(d) $\mathrm{t}=10 \mathrm{~s}$

Figure 7. Collapse Process of the Middle Tower Along Longitudinal Direction Under El Centro Wave

Under the Kobe wave, an element of main leg at $\mathrm{Z}=34.90 \mathrm{~m}$ yielded first at $4.58 \mathrm{~s}$. And then, at $5.06 \mathrm{~s}$, the element yielded first and a bracing component of diaphragm at $\mathrm{Z}=26.62 \mathrm{~m}$ lost the load-bearing capacity at the same time. From $5.06 \mathrm{~s}$ to $5.94 \mathrm{~s}$, most elements of diaphragm at $\mathrm{Z}=26.62 \mathrm{~m}$ lost the load-bearing capacity one by one. At $9.62 \mathrm{~s}$, the tower lost the vertical load transfer path.

Under Northbridge wave, at $3.62 \mathrm{~s}$, an element of main leg at $\mathrm{Z}=34.90 \mathrm{~m}$ yielded first. And then, at $3.77 \mathrm{~s}$, the element yielded first and a bracing component at $\mathrm{Z}=26.62 \mathrm{~m}$ lost load-bearing capacity at the same time. From $3.77 \mathrm{~s}$ to $5.11 \mathrm{~s}$, most elements of diaphragm at $\mathrm{Z}=26.62 \mathrm{~m}$ lost load-bearing capacity. A few elements of other locations lost load-bearing capacity in the process. From 5.11s, lots of elements lost load-bearing capacity. At $5.34 \mathrm{~s}$, the tower lost vertical load transfer path.

Under El Centro wave, at $2.25 \mathrm{~s}$, an element of main leg at $\mathrm{Z}=34.90 \mathrm{~m}$ yielded first. And then, at $9.12 \mathrm{~s}$, the element yielded first lost load-bearing capacity. From $9.12 \mathrm{~s}$ to $9.71 \mathrm{~s}$, a few elements lost load-bearing capacity. From 9.71s, lots of elements lost load-bearing capacity. At $9.96 \mathrm{~s}$, the tower lost vertical load transfer path. In the whole process, none elements of diaphragm at $\mathrm{Z}=26.62$ m lost load-bearing capacity.

From the analysis results, we can see, the main leg at $\mathrm{Z}=34.90 \mathrm{~m}$ is more prone to yield than other locations. What's more, the location is prone to lose load-bearing capacity. Under Kobe wave and Northbridge wave, the diaphragm at $\mathrm{Z}=26.62 \mathrm{~m}$ is prone to lose load-bearing capacity. It can be seen that the two locations are the potential vulnerable points of the tower. Therefore, the collapse-resistant capacity of the tower can be improved by strengthening or optimizing the two locations. Under El Centro wave, the diaphragm at $\mathrm{Z}=26.62 \mathrm{~m}$ is safe. It can be seen that the collapse routines of tower are different under different ground motion time histories. Therefore, three or more ground motion time histories should be used for collapse analysis of tower-line system.

\subsection{Collapse Analysis Along Lateral Direction}

In this section, the seismic records are inputted along lateral direction, and the ultimate strain of materials takes 0.02. Collapse process of the middle tower under Kobe, Northbridge and El Centro waves are shown in Figure 8, Figure 9 and Figure 10, respectively. 


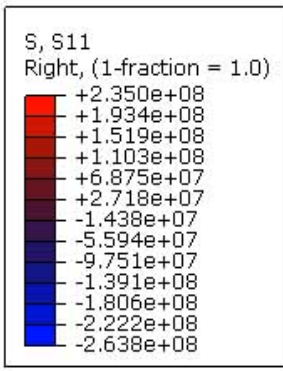

(a) $\mathrm{t}=7 \mathrm{~s}$

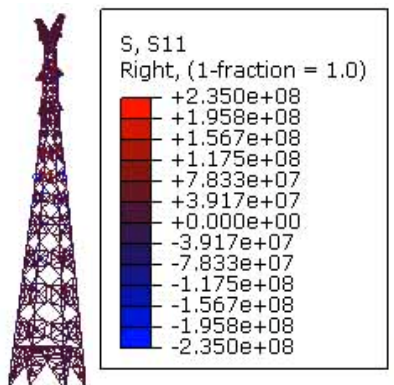

(b) $\mathrm{t}=7.2 \mathrm{~s}$

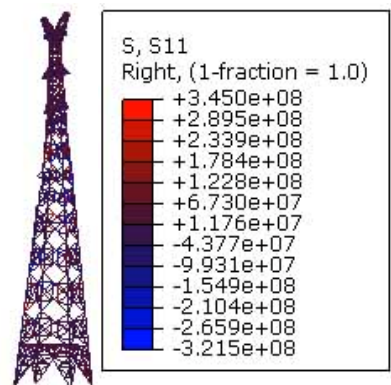

(c) $\mathrm{t}=8 \mathrm{~s}$

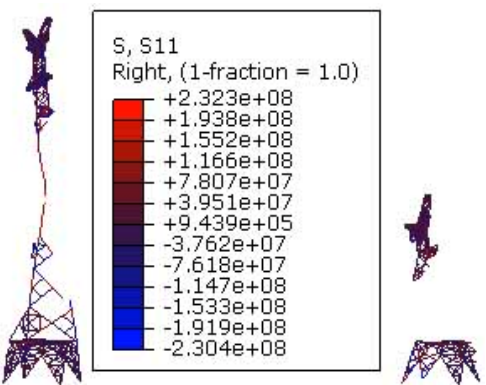

(d) $\mathrm{t}=10 \mathrm{~s}$

Figure 8. Collapse Process of the Middle Tower Along Lateral Direction Under Kobe Wave

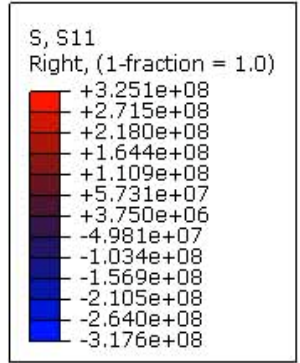

(a) $\mathrm{t}=4 \mathrm{~s}$

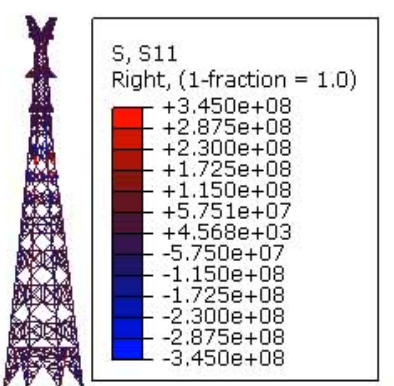

(b) $\mathrm{t}=4.5 \mathrm{~s}$

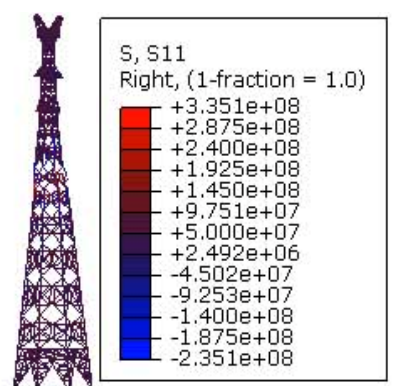

(c) $\mathrm{t}=5 \mathrm{~s}$

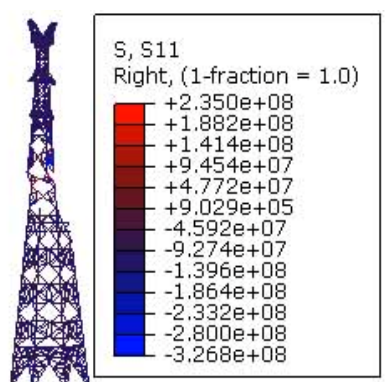

(d) $t=6 s$

Figure 9. Collapse Process of the Middle Tower Along Lateral Direction Under Northbridge Wave

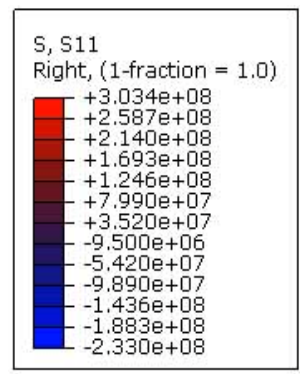

(a) $\mathrm{t}=5.5 \mathrm{~s}$

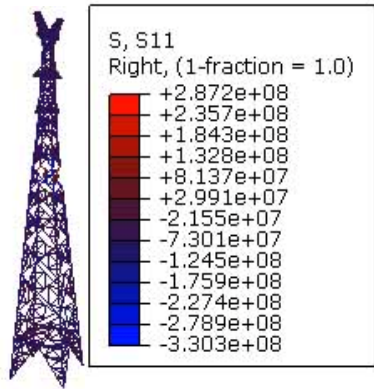

(b) $\mathrm{t}=6 \mathrm{~s}$

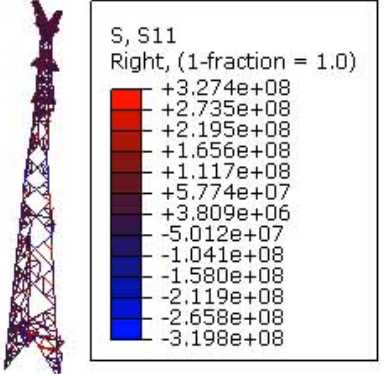

(c) $\mathrm{t}=6.5 \mathrm{~s}$

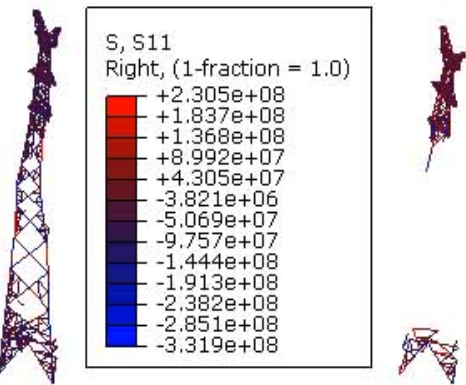

(d) $\mathrm{t}=7 \mathrm{~s}$

Figure 10. Collapse Process of the Middle Tower Along Lateral Direction Under El Centro Wave

Under Kobe wave, at $4.17 \mathrm{~s}$, an element of main leg at $\mathrm{Z}=34.90 \mathrm{~m}$ yielded first. And then, at $4.74 \mathrm{~s}$, the element yielded first lost load-bearing capacity. From $4.74 \mathrm{~s}$ to $7.17 \mathrm{~s}$, a few elements lost load-bearing capacity, and none elements of diaphragm at $\mathrm{Z}=26.62 \mathrm{~m}$ lost load-bearing capacity. From $7.17 \mathrm{~s}$, lots of elements lost load-bearing capacity. At $7.19 \mathrm{~s}$, most elements of diaphragm at $\mathrm{Z}=26.62 \mathrm{~m}$ lost load-bearing capacity. At $7.98 \mathrm{~s}$, the tower lost vertical load transfer path.

Under Northbridge wave, at $3.63 \mathrm{~s}$, an element of main leg at $\mathrm{Z}=34.90 \mathrm{~m}$ yielded first. And then, at $3.79 \mathrm{~s}$, the element yielded first lost load-bearing capacity. At $5.27 \mathrm{~s}$, the tower lost vertical load transfer path. In the whole process, none elements of diaphragm at $\mathrm{Z}=26.62 \mathrm{~m}$ lost load-bearing capacity.

Under El Centro wave, at $2.30 \mathrm{~s}$, an element of main leg at $\mathrm{Z}=34.90 \mathrm{~m}$ yielded first. At $3.67 \mathrm{~s}$, an element of diaphragm at $\mathrm{Z}=26.62 \mathrm{~m}$ lost load-bearing capacity. And then, at $3.68 \mathrm{~s}$, the element yielded first lost load-bearing capacity. From 5.71s, lots of elements lost load-bearing capacity. At $6.89 \mathrm{~s}$, the tower lost vertical load transfer path. It can be seen from Figure 10 and Figure 7 that the tower is easier to collapse along lateral direction for El Centro wave. 
The results above show that the element of main leg at $\mathrm{Z}=34.90 \mathrm{~m}$ and the diaphragm at $\mathrm{Z}=26.62 \mathrm{~m}$ are the potential vulnerable points of the tower. Under different ground motion time histories, the collapse routines of the tower along lateral direction are different.

\subsection{The Effect of Ultimate Strain on Collapse Routine and Collapse-resistant Capacity}

The ductility of material has a great influence on the performance of structure. The main objective of this section is to study the influences of ultimate strain of material on collapse routine and capacity of the tower-line system. The ultimate strain used above takes 0.02, and used in this section is 0.1 . Kobe wave is used only and inputted along lateral direction. The collapse process is shown in Figure 11.

At $\mathrm{t}=4.17 \mathrm{~s}$, an element of main leg at $\mathrm{Z}=34.90 \mathrm{~m}$ yielded first, which is the same as the result when ultimate strain takes 0.02 . At $\mathrm{t}=5.05 \mathrm{~s}$, an element of diaphragm at $\mathrm{Z}=26.62 \mathrm{~m}$ lost load-bearing capacity. At $\mathrm{t}=6.68 \mathrm{~s}$, all elements of diaphragm at $\mathrm{Z}=26.62 \mathrm{~m}$ lost load-bearing capacity. Comparing it with the result when ultimate strain takes 0.02 , the influence of ultimate strain to collapse routine is obvious. In the whole process, none element of the main leg lost load-bearing capacity. It is obvious that the collapse-resistant capacity of the structure increases remarkably with the increase of ultimate strain.

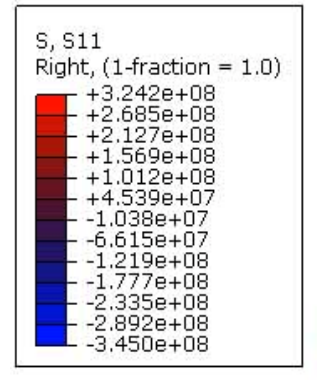

(a) $\mathrm{t}=7 \mathrm{~s}$

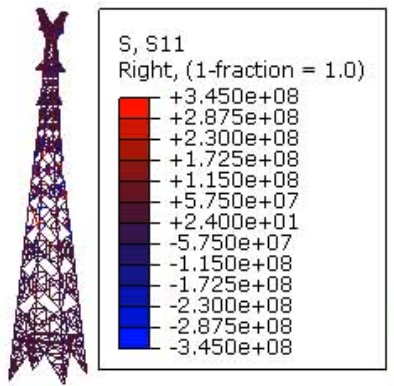

(b) $\mathrm{t}=7.2 \mathrm{~s}$

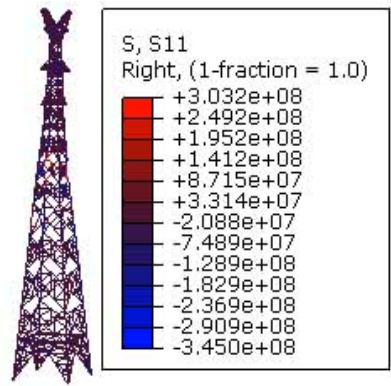

(c) $\mathrm{t}=8 \mathrm{~s}$

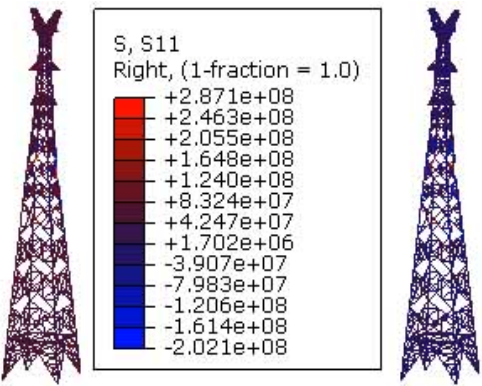

(d) $t=10 \mathrm{~s}$

Figure 11. Collapse Process of the Middle Tower Along Lateral Direction Under Kobe Wave (ultimate strain is 0.1)

\subsection{Effect of Strain Rate on Collapse Mode and Collapse-resistant Capacity}

Most materials used in civil engineering are sensitive to strain rate. Over the past decade, many researchers studied dynamic properties of the HPB235, HRB335 and HRB400 (Lin et al. [19]; Li and $\mathrm{Li}[20])$. The results showed that different types of steel have different sensitivities to the strain rate; the yield strength and tensile strength increase with the increase of strain rate; generally, the lower the yield strength is, the more obvious of the sensitivity is; the Young's modulus is almost invariable with the increase of strain rate. For dynamic phenomena, using dynamic constitutive relation is more rational than using static constitutive relation, and the mechanism lies in that the stiffness matrix is relative to strain rate. Bhowmick et al. investigated the effect of loading rate on the dynamic behavior of steel plate shear wall by the non-linear dynamic analysis using the ABAQUS software, which revealed that the ductility of structure reduced and the average flexural demand at the base of the wall increased with higher strain rates (Bhowmick et al. [21]). In this paper, we studied the effect of strain rate on the collapse mode and collapse-resistant capacity of transmission tower-line system under earthquake. 
Under earthquake, the strain rate of steel is hard to exceed 1/s. The dynamic constitutive relationship model incorporated in the finite element analysis is as follows ( $\mathrm{Li}$ and $\mathrm{Li}[20]$ ):

$$
\begin{aligned}
& f_{y d}=\left(1+c_{f} \lg \frac{\dot{\varepsilon}}{\dot{\varepsilon}_{0}}\right) f_{y s} \\
& c_{f}=0.1709-3.289 \times 10^{-4} f_{y s}
\end{aligned}
$$

where $\dot{\varepsilon}$ is the current strain rate; $\dot{\varepsilon}_{0}$ is the quasi-static strain rate, $\dot{\varepsilon}_{0}=2.5 \times 10^{-4} / \mathrm{s} ; f_{y s}$ is the yield strength at quasi-static strain rate; $f_{y d}$ is the dynamic yield strength at the current strain rate.

In this section, the ultimate strain used is 0.02 . The Kobe wave is used only and input along lateral direction. Figure 12 shows the collapse process of middle tower considering strain rate effect.
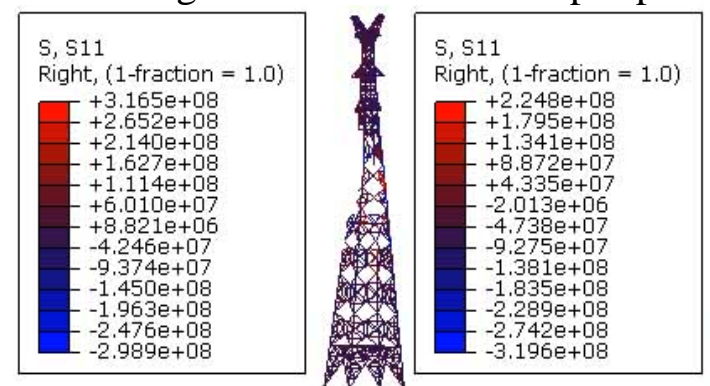

(a) $\mathrm{t}=7 \mathrm{~s}$ (b) $\mathrm{t}=7.2 \mathrm{~s}$

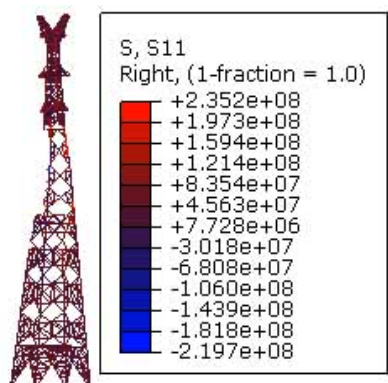

(c) $\mathrm{t}=8 \mathrm{~s}$

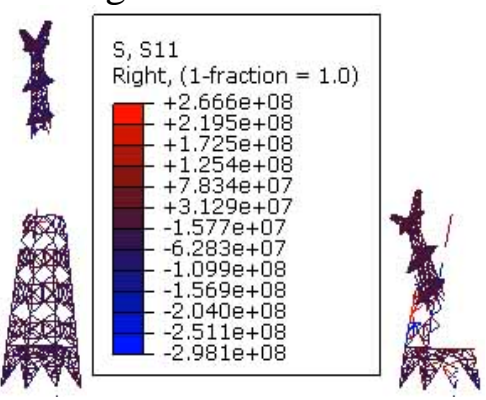

(d) $\mathrm{t}=10 \mathrm{~s}$

Figure 12. Collapse Process of the Middle Tower Along Lateral Direction Under Kobe Wave（with strain rate effect）

At $4.19 \mathrm{~s}$, an element of main leg at $\mathrm{Z}=34.90 \mathrm{~m}$ yielded first. It can be seen that the time was delayed slightly while the location was unchanged after considering strain rate effect. At $4.74 \mathrm{~s}$, the element yielded first lost load-bearing capacity, which is unchanged after considering strain rate effect. At $4.82 \mathrm{~s}$, some elements of diaphragm at $\mathrm{Z}=26.62 \mathrm{~m}$ lost load-bearing capacity, which is different with the result without considering strain rate effect. At $7.86 \mathrm{~s}$, the tower lost vertical load transfer path, which is earlier than the result without considering strain rate effect. It can be seen from Figure 12(d) and Figure 8(d) that there were more elements that still had load-bearing capacity at the end of the analysis.

Based on the above analysis, it is obvious that the influences of strain rate effect on collapse routine and collapse-resistant capacity of transmission tower-line system are tiny.

\section{CONCLUSIONS}

In this paper, a progressive collapse analysis procedure based on the FEM is proposed, by which the failure process of transmission tower-line system caused by the earthquake can be simulated to understand the collapse mechanism. During this procedure, the mass of the elements is still retained rather than removal after elements lose the load-bearing capacity. By applying the proposed approach, the progressive collapse analysis of a tower-line system is conducted. From the numerical results obtained, the following conclusions are drawn: 
(1) Using the proposed procedure, vulnerable points and collapse modes of tower-line system can be determined. Thereby, the proposed procedure is effective, which can be used for the design of a new tower or for checking the capacity of an existing tower.

(2) Under different seismic records, collapse modes and vulnerable points of transmission tower are different. To obtain more potential collapse modes and vulnerable points, three or more seismic records should be used for the collapse analysis of tower-line system.

(3) Influences of ultimate strain on the collapse mode and collapse-resistant capacity are obvious. With different ultimate strains, the collapse modes are different; the collapse-resistant capacity of structure increases remarkably with the increase of ultimate strain.

(4) The comparisons between the results considering the strain rate effect and the results without strain rate effect show that the strain rate effect on the collapse mode and capacity of transmission tower-line system are tiny.

\section{ACKNOWLEDGEMENT}

This research work was jointly supported by the National Natural Science Foundation of China (Grant No. 90815026, 50638010 and 51208285) and Key International Collaboration Project (Grant No. 51261120375), National Key basic Research and Development Program (973 Program) (Grant No. 2011CB013605) and the Science Fund for Creative Research Groups of the National Natural Science Foundation of China (Grant No. 51121005).

\section{REFERENCES}

[1] Li, H.N. and Bai, H.F., "State-of-the-art Review on Studies of Disaster resistance of High-voltage Transmission Tower-line Systems”, China Civil Engineering Journal, 2007, Vol. 40, No. 2, pp. 39-46.

[2] Xie, Q. and Li, J., "Current Situation of Natural Disaster in Electric Power System and Counter Measures”, Journal of Natural Disasters, 2006, Vol. 15, No. 4, pp. 126-131.

[3] Li, H.N., Hu, D. Zh. and Huang, L. Zh., "Plastic Limit Analysis of the Transmission Tower System Subjected to Earthquake Action”, Proceedings of the CSEE, 2006, Vol. 26, No. 24, pp. 192-199.

[4] Albermani, F., Kitipornchai, S. and Chan, R.W.K., "Failure Analysis of Transmission Towers”, Engineering Failure Analysis, 2009, Vol. 16, No. 6, pp. 1922-1928.

[5] Rao, N.P., Knight, G.M.S., Lakshmanan, N. and Iyer, N.R., "Investigation of Transmission Line Tower Failures”, Engineering Failure Analysis, 2010, Vol. 17, No. 5, pp. 1127-1141.

[6] Cundall, P.A. and Strack, O.D.L., “A Distinct Numerical Model for Granular Assemblies”, Geotechnique, 1979, Vol. 29, No. 1, pp. 47-65.

[7] Meguro, K. and Hakuno, M., "Fracture Analysis of Concrete Structures by the Modified Distinct Element Method”, Structural Engineering / Earthquake Engineering, 1989, Vol. 6, No. 2, pp. 283-294.

[8] Munjiza, A., Owen, D.R.J. and Bicanic, N., "A Combined Finite-Discrete Element Method in Transient Dynamics of Fracturing Solids”, Engineering Computions, 1995, Vol. 12, No. 2, pp. 145-174.

[9] Munjiza, A., Bangash, T. and John, N.W.M., "The Combined Finite-Discrete Element Method for Structural Failure and Collapse”, Engineering Fracture Mechanics, 2004, Vol. 71, No. 4-6, pp. 469-483. 
[10] Meguro, K. and Tagel-Din, H., “Applied Element Method for Structural Analysis: Theory and Application for Linear Materials”, Struct Engrg./Earthquake Engrg., 2000, Vol. 17, No. 1, pp. 21s-35s.

[11] Meguro, K. and Tagel-Din, H., “Applied Element Simulation of RC Structures Under Cylic Loading”, Journal of Structural Engineering, 2001, Vol. 127, No. 11, pp. 1295-1305.

[12] Sun, J.S., Lee, K.H. and Lee H.P., "Comparison of Implicit and Explicit Finite Element Methods for Dynamic Problems”, Journal of Material Processing Technology, 2000, Vol. 105, No. 1-2, pp. 110-118.

[13] Lu, X. Zh., Lin, X.Ch., Ye, L.P., Li, Y. and Tang D.Y., "Numerical Models for Earthquake Induced Progressive Collapse of High-rise Buildings”, Engineering Mechanics, 2010, Vol. 27, No. 11, pp. 64-70.

[14] Kwasniewski, L., "Nonlinear Dynamic Simulations of Progressive Collapse for a Multistory Building”, Engineering Structures, 2010, Vol. 32, No. 5, pp. 1223-1235.

[15] Marjanishvili, S. and Aganew, E., "Comparison of Various Procedures for Progressive Collapse Analysis”, Journal of Performance of Constructed Facilities, 2006, Vol. 20, No. 4, pp. 365-374.

[16] ABAQUS Inc., “ABAQUS Analysis User’s Manual”, ABAQUS Inc., 2010.

[17] Shen, G.H., Sun B.N., He, Y.X., Ye, Y. and Lou, W.J., "Seismic Response of Long-Span Transmission Tower-Line System”, Engineering Mechanics, 2008, Vol. 25, No. 11, pp. 212-217.

[18] Tian, L., Li, H.N. and Liu, G.H., "Seismic Response of Power Transmission Tower-Line System Subjected to Varying Ground Motions”, Mathematical Problems in Engineering, 2010, Article ID 587317.

[19] Lin, F., Gu, X.L., Kuang, X.X. and Yin, X.J., "Constitutive Models for Reinforcing Steel Bars Under High Strain Rates”, Journal of Building Materials, 2008, Vol. 11, No. 1, pp. 14-20.

[20] Li, M. and Li, H.N., “Dynamic Test and Constitutive Model for Reinforcing Steel”, China Civil Engineering Journal, 2010, Vol. 43, No. 4, pp. 70-75.

[21] Bhowmick, A.K., Driver, R.G. and Grondin, G.Y., "Seismic Analysis of Steel Plate Shear Walls Considering Strain Rate and P-Delta Effects”, Journal of Constructional Steel Research, 2009, Vol. 65, No. 5, pp. 1149-1159. 